\title{
Evaluation of the Elemental Impurities of the Drug Captopril Marketed Commercialized in Rio de Janeiro, Brazil
}

\author{
Santos, L. M. G.;* Iozzi, G. M.; Vicentini Neto, S. A.; Jacob, S. C.
}

Rev. Virtual Quim., 2018, 10 (3), 698-708. Data de publicação na Web: 29 de junho de 2018

http://rvq.sbq.org.br

\section{Avaliação das Impurezas Elementares do Medicamento Captopril Comercializadas na Cidade do Rio de Janeiro, Brasil}

Resumo: O objetivo desse trabalho foi avaliar e validar metodologia analítica para determinar impurezas elementares em IFAs e produto final de captopril, tendo como base as novas diretrizes da Farmacopeia Americana. As técnicas escolhidas para este fim foram a espectrometria de emissão óptica com plasma indutivamente acoplado (ICP OES) e a espectrometria de absorção atômica com forno de grafite (GF AAS). Os resultados indicam que os métodos possuem sensibilidade, precisão (1.5-10\%) e exatidão (86-120\%) adequadas para avaliar os elementos inorgânicos nas amostras desejadas. Todas as amostras analisadas apresentaram resultados inferiores ao limite de quantificação das técnicas utilizadas para maioria dos elementos, com exceção do ferro que apresentou resultados superiores ao limite de quantificação da técnica ICP OES $\left(10 \mu g \mathrm{~L} \mathrm{~L}^{-1}\right)$.

Palavras-chave: Impurezas elementares; ICP OES; GF AAS; Captopril; Validação.

\begin{abstract}
The aim of the present study was to evaluate and validates an analytical methodology to determine elemental impurities in IFAs and final product of captopril, able to meet the current guidelines of the American pharmacopoeia. The techniques chosen for this end were inductively coupled plasma optical emission spectrometry and graphite furnace atomic absorption spectrometry. The results indicate that the methods have adequate sensitivity, precision (1.5-10\%) and accuracy (86-120\%) to evaluate the inorganic elements in the desired samples. All analyzed samples presented results below the limit of quantification of the techniques for most of the elements, except iron hat the value was greater than the limit of quantification $\left(10 \mu \mathrm{gL}^{-1}\right)$.
\end{abstract}

Keywords: Elemental impurities; ICP OES; GF AAS; Captopril; Validation.

* Fundação Osvaldo Cruz, Instituto Nacional de Controle de Qualidade em Saúde, Departamento Químico, Av. Brasil 4365, Manguinhos, CEP 21040-900, Rio de Janeiro-RJ, Brasil.

Mlisia.gobbo@incqs.fiocruz.br

DOI: $\underline{10.21577 / 1984-6835.20180051}$

Rev. Virtual Quim. |Vol 10| |No. 3| |698-708| 
Volume 10, Número 3

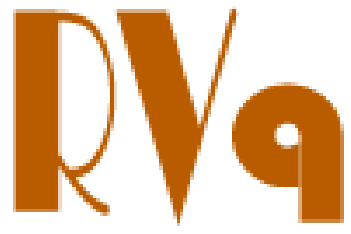

Maio-Junho 2018

Revista Virtual de Química

ISSN 1984-6835

\section{Evaluation of the Elemental Impurities of the Drug Captopril Marketed Commercialized in Rio de Janeiro, Brazil}

\section{Lisia Maria Gobbo dos Santos, * Giovanna lozzi, Santos Alves Vicentini Neto, Silvana do Couto Jacob}

Fundação Osvaldo Cruz, Instituto Nacional de Controle de Qualidade em Saúde, Departamento Químico, Av. Brasil 4365, Manguinhos, CEP 21040-900, Rio de Janeiro-RJ, Brasil.

* lisia.gobbo@incqs.fiocruz.br

Recebido em 15 de março de 2018. Aceito para publicação em 25 de junho de 2018

1. Introduction

2. Material and Methods

2.1. Sample

2.2. Instrumentation

2.3. Reagents and standards

2.4. Method Validation

2.5. Estimated permissible daily exposures (PDE) for toxic elements through drugs

\section{Results and Discussion}

3.1. Method Validation

3.2. Product analysis and active pharmaceutical ingredient API quantitation

\section{Conclusions}

\section{Introduction}

During the development and manufacturing of pharmaceuticals, several contamination sources may lead to product contamination by inorganic impurities. ${ }^{1}$ These impurities can often produce undesirable effects, impairing or even nullifying the benefits sought out when administering a drug. Toxic metals in pharmaceuticals, such as lead and cadmium, pose serious health hazards, even at very low doses. $^{2} \quad$ Lead exposure may cause cardiovascular effects, increased blood pressure and incidence of hypertension, decreased kidney function and reproductive problems, in both men and women ${ }^{3-4}$, while cadmium is a human carcinogen associated to serious health hazard risks. Experimental and epidemiological evidence strongly suggest that the biological half-life of this element in the body is extremely high, of approximately 10 years or more. ${ }^{5-7}$

In order to control these impurities, it is essential to obtain specific quantitative information for each analyte, not only to meet legislation specifications, but also the for pharmaceutical industry needs, that are required to provide for the safety and 
effectiveness of medicinal products intended for human consumption. The permissible levels of heavy metals in pharmaceuticals are usually defined by regulatory agencies and controlled by limit tests. Methods involve the precipitation of metal sulfides from an aqueous solution and visual color comparison to that of a simultaneously and similarly treated standard lead solution. This method is non-specific, less sensitive, time-consuming and less accurate. ${ }^{2}$

In 2014, the United States Pharmacopeia (USP) proposed several changes to the methods used for the determination of elemental impurities. New limits for inorganic contaminants have been proposed by USP chapters 232 (limits) $^{8}$ and 233 (procedures) ${ }^{9}$, as well as by chapter 5.20 of the European Medicines Agency (EMA).$^{10-11}$ These chapters emphasize the importance of assessing elemental impurities not only in active pharmaceutical ingredients and excipients, but also in final pharmaceutical products, aiming at the possibility of risk, considering the oral permissible daily exposures (PDEs). Examples of this include Gonzales (2017) ${ }^{12}$ regarding acyclovir ointment samples and raw materials, Tavares $(2013)^{13}$ for radipharmaceuticals and Gang $(2015)^{14}$ for pharmaceutical excipients.

In this context, the aim of the present study was to evaluate and validate if the GF AAS and ICP OES are analytical methodologies able to meet the current USP guidelines regarding the analysis of elemental impurities (As, Cd, Pb, Ba, Co, Cu, Cr, Fe, Li, Ni and $\mathrm{V}$ ) in captopril and captopril API. Captopril is one of the most commonly used (chronic) drugs in Brazil used against arterial hypertension, available from the National Health System (SUS) ${ }^{15}$, and is included in the National Program for the Verification of the Quality of Medicines (PROVEME). ${ }^{16}$

\section{Material and Methods}

\subsection{Sample}

Six different final pharmaceutical products were analyzed, three generic drugs $(A, B$ and $C)$ and three hybrid drugs ( $D, E$ and $F$ ). Among the 6 selected manufacturers, 2 (A and $B$ ) were chosen for a batch evaluation, in which 3 different drug lots were purchased and evaluated. In addition to the drugs selected for analysis, the active pharmaceutical ingredients (API) of lot C3F01, obtained from the Reference Chemical Substances Sector (SQR) of the National Institute of Quality Control in Health -INCQS/Fiocruz, were also analyzed. The samples were collected by the State Sanitary Surveillance Secretaries in drugstores located in the cities of Niteroi and Rio de Janeiro. The chemical analyses were carried out at the Inorganic Elements Sector of the Chemistry Department of the INCQS/Fiocruz.

The samples were homogenized and stored in suitable containers (Falcon tubes). Approximately $0.3 \mathrm{~g}$ of each sample, in duplicate, were weighed in Teflon tubes and $5 \mathrm{~mL}$ of nitric acid 65\% (p/v) (Merck, Germany) were added, along with $3 \mathrm{~mL}$ of hydrogen peroxide 30\% (Merck, Germany). The samples were then digested in a highpressure closed system, microwave (SpeedWave, Berghof, Germany). After cooling, the sample solutions were transferred to $15.00 \mathrm{~mL}$ of the type falcon and completed with deionized water.

\subsection{Instrumentation}

Inductively Coupled Plasma Optical Emission Spectrometry- ICP OES (Optima 8300, PerkinElmer, USA) was used for the determination of $\mathrm{Ba}, \mathrm{Co}, \mathrm{Ni}, \mathrm{Cu}, \mathrm{Cr}, \mathrm{Fe}, \mathrm{Li}$ and $\mathrm{V}$, while $\mathrm{As}, \mathrm{Cd}$ and $\mathrm{Pb}$ were determined using Graphite Furnace Atomic Absorption Spectrometry - GF AAS (PinAAcle 900Z, Perkin Elmer, USA), equipped with an auto sampler (AS 900), a transverse-heated graphite furnace with an Integrated Platform and longitudinal Zeeman background correction. The instrument parameters for the ICP OES and GF AAS analyses are displayed in Tables 1 and 2, respectively. 
Table 1. Inductively Coupled Plasma Optical Emission Spectrometry (ICP OES) parameters for the analysis of $\mathrm{Ba}, \mathrm{Co}, \mathrm{Ni}, \mathrm{Cu}, \mathrm{Cr}, \mathrm{Fe}$, $\mathrm{Li}$ and $\mathrm{V}$.

\begin{tabular}{cc}
\hline Plasma Power & $1300 \mathrm{~W}$ \\
Nebulizer gas & $0.55 \mathrm{~L} / \mathrm{min}$ \\
Auxiliary gas & $0.2 \mathrm{~L} / \mathrm{min}$ \\
Plasma gas & $15.0 \mathrm{~L} / \mathrm{min}$ \\
Nebulizer & Meinhard \\
Spray chamber & Cyclonic \\
Plasma view & Axial \\
\hline
\end{tabular}

Table 2. Graphite Furnace Atomic Absorption Spectrometry (GF AAS) parameters for the analysis of $\mathrm{As}, \mathrm{Cd}$ and $\mathrm{Pb}$.

\begin{tabular}{|c|c|c|c|}
\hline & As & $\mathrm{Cd}$ & $\mathrm{Pb}$ \\
\hline Sample volume & $20 \mu \mathrm{L}$ & $20 \mu \mathrm{L}$ & $20 \mu \mathrm{L}$ \\
\hline Modifier volume & $5 \mu \mathrm{L}$ of each & $5 \mu \mathrm{L}$ of each & $5 \mu \mathrm{L}$ of each \\
\hline Pyrolysis & 1200 으 & $750 \stackrel{\circ}{C}$ & $850 \stackrel{\circ}{C}$ \\
\hline Atomization & $2300 \circ \mathrm{C}$ & $1500 \div \mathrm{C}$ & $1600 \div \mathrm{C}$ \\
\hline \multirow[t]{2}{*}{ Matrix Modifier } & $0.6 \mathrm{~g} / \mathrm{L} \mathrm{Mg}\left(\mathrm{NO}_{3}\right)_{2}+$ & $1 \% \mathrm{NH}_{4} \mathrm{H}_{2} \mathrm{PO}_{4}+$ & $1 \% \mathrm{NH}_{4} \mathrm{H}_{2} \mathrm{PO}_{4}+$ \\
\hline & $1 \mathrm{~g} / \mathrm{L} \mathrm{Mg}\left(\mathrm{NO}_{3}\right)_{2}$ & $0.6 \mathrm{mg} / \mathrm{L} \mathrm{Mg}\left(\mathrm{NO}_{3}\right)_{2}$ & $0.6 \mathrm{mg} / \mathrm{L} \mathrm{Mg}\left(\mathrm{NO}_{3}\right)_{2}$ \\
\hline Measurement & Peak Area & Peak Area & Peak Area \\
\hline Lamp & *EDL & *EDL & *EDL \\
\hline
\end{tabular}

* Electrodeless Discharge Lamp

\subsection{Reagents and standards}

Deionized water produced on a Milli- ${ }^{\circledR}$ System (Bedford, MA, USA) was used to prepare all solutions. All glassware was immersed in $10 \%(\mathrm{v} / \mathrm{v}) \mathrm{HNO}_{3}$ for $36 \mathrm{~h}$ and rinsed with water. All reagents and solutions were prepared with analytical-grade reagents from Merck (Darmstadt, Germany). A multielement calibration standard solution (Perkin Elmer - $10 \mathrm{mgL}^{-1}$ ) and mono-element As, Cd and $\mathrm{Pb}$ solutions, $1000 \mathrm{mg} \mathrm{L}^{-1}$, were employed (Merck). White Martins (SP, Brazil) provided argon (99.999\%) gas used for ICP OES and GF AAS analyses.

\subsection{Method validation}

The developed analytical method was validated according to the same parameters as described in USP chapter $<233\rangle$, DOQCGCRE-008 INMETRO and ISO $17025 .{ }^{17-18}$ The analytical performance of the method was evaluated for each sample batch, through a recovery study.

Linearity was tested according to the studies by Souza (2005) ${ }^{19}$ and Bazilio (2012). ${ }^{20}$ Regression parameters were estimated by the ordinary least squares (OLS) method at a significance level of 0.05 , which requires regression residuals to follow a normal 
distribution. Prior to linearity evaluations, however, the presence of discrepant values for each level of concentration is determined. Outliers were diagnosed by the Jacknifee standardized residue test applied successively until new outliers were detected or up to a maximum exclusion of $22.2 \%$ in the original number of data. ${ }^{20}$ Subsequently, linearity was evaluated by three independent analytical curves with 5 calibration points each and three readings for each point. For analysis by ICP OES the calibration points are $30,50,80,100$ and $150 \mu \mathrm{g} \mathrm{L^{- }}$ for analysis by GF AAS for As $\left(2,5,10,15,20 \mu \mathrm{g} \mathrm{L}^{-1}\right)$ for $\mathrm{Cd}$ $\left(0,5,1,2,3,5 \mu \mathrm{g} \mathrm{L}^{-1}\right)$ for $\mathrm{Pb}(5,10,20,40,50 \mu \mathrm{g} \mathrm{L}$ $\left.{ }^{1}\right)$.

The limit of detection (LOD) of the method was calculated as three times the standard deviation of the measured concentration for ten replicate blank samples for $\mathrm{As}, \mathrm{Cd}, \mathrm{Pb}, \mathrm{Ba}, \mathrm{Fe}$ and $\mathrm{Li}$. For $\mathrm{Co}, \mathrm{Cr}, \mathrm{Cu}, \mathrm{Ni}$ and $\mathrm{V}$ the limit of detection was calculated experimentally by means of successive dilutions. The limit of quantitation (LOQ) was calculated as ten times the standard deviation for $\mathrm{As}, \mathrm{Cd}, \mathrm{Pb}, \mathrm{Ba}$, Fe and Li. For $\mathrm{Co}$, $\mathrm{Cr}, \mathrm{Ni}$ and $\mathrm{V}$, determined experimentally. ${ }^{17}$
The accuracy of the analytical method was also evaluated through recovery calculations using spiked drug samples at three different concentration levels, 30, 70 and $150 \mathrm{\mu g} \mathrm{L}^{-1}$ for ICP OES and 2.0, 5.0 and $20 \mu \mathrm{g} \mathrm{L}^{-1}$ for As, 5.0, 20 and $50 \mu \mathrm{L} \mathrm{L}^{-1}$ for $\mathrm{Pb}$ and $0.5,2.0,5.0 \mu \mathrm{g} \mathrm{\textrm {L } ^ { - }}$ 1 for $\mathrm{Cd}$, before microwave-assisted digestion. ${ }^{9,17}$ Three independent solutions were prepared for each concentration level and three solutions for each were prepared. These experiments were performed in order to evaluate analyte loss during sample digestion and to evaluate possible spectral interferences that can occur in the determinations.

Precision was evaluated using repeatability (relative standard deviation RSD). Repeatability was evaluated using seven independent samples, and the means and standard deviations of the results were calculated in order to obtain the RSD. ${ }^{9,17}$

In order to calculate the final relative uncertainty, all uncertainty sources of the performed methodology were considered (Figure 1). ${ }^{21}$

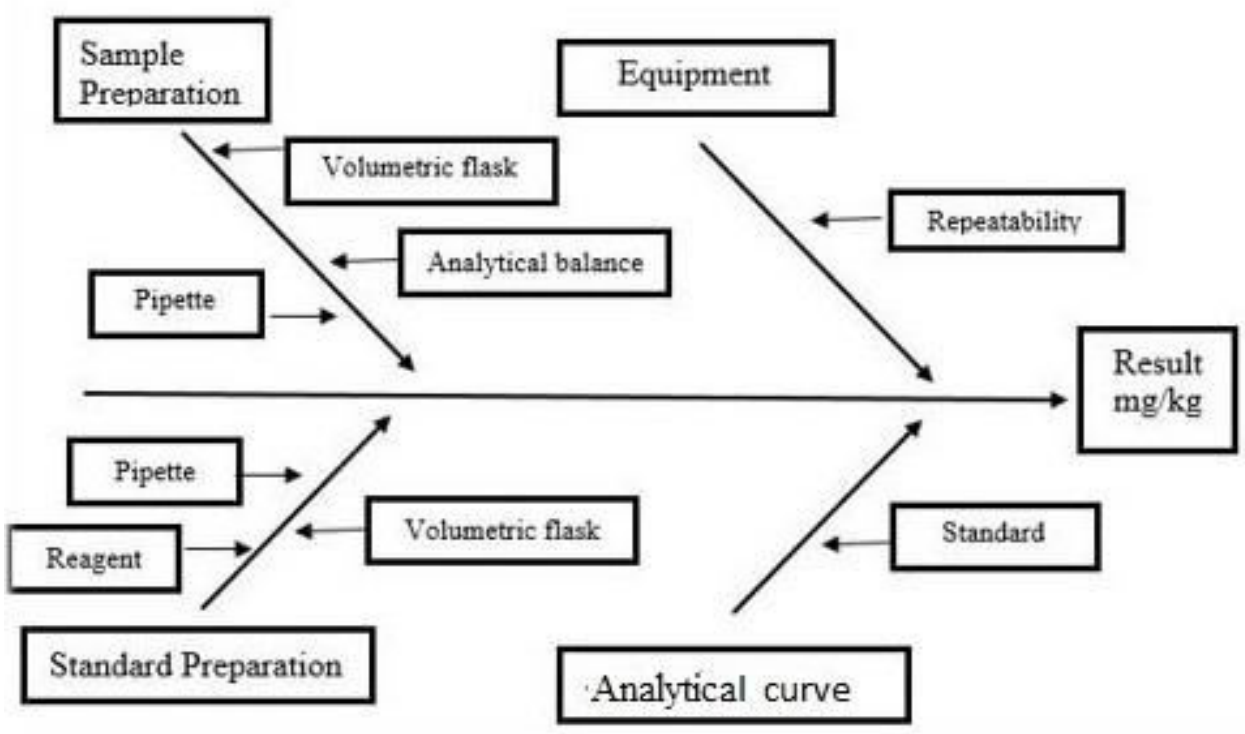

Figure 1. Cause and effect diagram for the uncertainty calculations of the present study 
All data were tested regarding normal distribution normal (Ryan-Joiner test), homogeneity of variance (Levene and BrownForsythe's tests) and analyses of variance $\left(\right.$ ANOVA) ${ }^{20}$.

2.5. Estimated permissible daily exposures (PDE) for toxic elements through drugs

$$
\operatorname{PDE} \geq \operatorname{Cce}\left(\frac{\mu \boldsymbol{g}}{\boldsymbol{g}}\right) \times \operatorname{Dd}\left(\frac{\boldsymbol{g}}{\boldsymbol{d a y}}\right)
$$

Where PDE is the oral permissible daily exposure $(\mu \mathrm{g} /$ day), Cce is the concentration of the chemical element; and Dd is the daily dose. USP <232> establishes daily concentration limits $\left(\mu \mathrm{g} \mathrm{g}^{-1}\right)$ for drug substances and excipients, with a maximum daily element dose of $\leq 10 \mathrm{~g}$ per day, based on a $50 \mathrm{~kg}$ person.

\section{Results and Discussion}

\subsection{Method Validation}

Aberrant values were disregarded and statistical tests concerning linearity were performed. All elements were homoscedastic and exhibited no autocorrelation, as evaluated by the normality of residues by the
The first conducted test was weight determination, in order to verify if the units of the same batch are uniform in weight. Twenty tablets were weighed individually, and the average weight was determined.

The permissible daily exposures were calculated through the equation 1.

\section{Equation 1}

Ryan-Joiner test and the homogeneities of the results by the Levene and BrownForsythe's test. An ANOVA test was carried out to confirm the linearity of the constructed curves, with results presenting $p$ $<0.001$, indicating that the curve regression is significant, while $p>0.05$ that demonstrates no linearity deviation. Table 3 presents the equations of the line obtained herein, as well as the coefficient of determination $\left(R^{2}\right)$, higher than 0.9990, indicating that the analytical curves present adequate linearity according to the document of INMETRO. ${ }^{17}$

The limits of detection, limited of quantification, relative standard deviations and estimated permissible daily exposures (PDE) are displayed in Table 4. Accuracy values for the developed method are displayed in Table 5.

Table 3. Equations of the line, coefficients of determination $\left(R^{2}\right)$ and the linear working range for each element obtained in the present study

\begin{tabular}{cccc}
\hline Element & $\begin{array}{c}\text { Straight line equation } \\
\mathbf{Y}=\mathbf{a}+\mathbf{b x}\end{array}$ & $\mathbf{R}^{\mathbf{2}}$ & $\begin{array}{c}\text { Linear range } \\
\left(\mu \mathrm{L} \mathrm{L}^{-1}\right)\end{array}$ \\
\hline $\mathrm{As}$ & $\mathrm{Y}=0.0006+0.0027 x$ & 0.9996 & $2-20$ \\
$\mathrm{Cd}$ & $\mathrm{Y}=0.00004+0.0630 \mathrm{x}$ & 0.9998 & $0.5-5$ \\
$\mathrm{~Pb}$ & $\mathrm{Y}=0.0049+0.0029 \mathrm{x}$ & 0.9998 & $5-50$ \\
$\mathrm{Ba}$ & $\mathrm{Y}=-57.82+103773 \mathrm{x}$ & 0.9998 & \\
\hline \hline
\end{tabular}




\begin{tabular}{|c|c|c|c|}
\hline Co & $Y=-242.21+51359 x$ & 0.9997 & \\
\hline $\mathrm{Cu}$ & $Y=82.07+106256 x$ & 0.9995 & \\
\hline $\mathrm{Cr}$ & $Y=-225.50+68717 x$ & 0.9997 & $30-150$ \\
\hline $\mathrm{Fe}$ & $Y=396.89+121401 x$ & 0.9991 & \\
\hline Li & $Y=9621.97+11050707 x$ & 0.9995 & \\
\hline $\mathrm{Ni}$ & $Y=-204.28+34588 x$ & 0.9992 & \\
\hline V & $Y=114.22+132067 x$ & 0.9998 & \\
\hline
\end{tabular}

$\mathrm{b}=$ slope $/ \mathrm{a}=$ linear coefficient

Table 4. Analytical performance, the oral permissible daily exposures (PDEs) and figures of merit for $\mathrm{As}, \mathrm{Cd}, \mathrm{Pb}$ for GF AAS and $\mathrm{Ba}, \mathrm{Co}, \mathrm{Cu}, \mathrm{Cr}$, Fe, Li, Ni, $\mathrm{V}$ for ICP OES

\begin{tabular}{ccccccc}
\hline Element & $\begin{array}{c}\text { Wavelengths } \\
(\mathbf{n m})\end{array}$ & $\begin{array}{c}\text { Precision }(\mathrm{n}=7) \\
(\% \mathrm{RSD})\end{array}$ & $\begin{array}{c}\text { LOD } \\
\left(\mu \mathrm{g} \mathrm{L}^{-1}\right)\end{array}$ & $\begin{array}{c}\text { LOQ } \\
\left(\mu \mathrm{g} \mathrm{L}^{-1}\right)\end{array}$ & $\begin{array}{c}\mathrm{PDE}^{\mathrm{A}} \\
(\mu \mathrm{g} / \mathrm{day})\end{array}$ & $\begin{array}{c}\mathrm{PDE}^{\mathrm{B}} \\
(\mu \mathrm{g} / \mathrm{day})\end{array}$ \\
\hline $\mathrm{As}^{*}$ & 193.7 & 4.5 & 0.5 & 2 & 0.6 & 15 \\
$\mathrm{Cd}^{*}$ & 228.8 & 2.5 & 0.05 & 0.5 & 0.2 & 5 \\
$\mathrm{~Pb}^{*}$ & 283.3 & 1,5 & 1.5 & 5 & 1.6 & 5 \\
$\mathrm{Ba}$ & 233.5 & 3.5 & 0.5 & 2 & 0.6 & 1400 \\
$\mathrm{Co}$ & 228.6 & 2.6 & 10 & 30 & 3 & 50 \\
$\mathrm{Cu}$ & 327.3 & 4.0 & 10 & 30 & 3 & 3000 \\
$\mathrm{Cr}$ & 267.7 & 3.0 & 10 & 30 & 3 & 11000 \\
$\mathrm{Fe}$ & 238.2 & 10 & 1.3 & 4 & 1 & ------- \\
$\mathrm{Li}$ & 670.7 & 3.5 & 2.2 & 7 & 2 & 550 \\
$\mathrm{Ni}$ & 231.6 & 2.5 & 10 & 30 & 3 & 200 \\
$\mathbf{V}$ & 292.4 & 3.0 & 10 & 30 & 3 & 100 \\
\hline
\end{tabular}

*Analysis by GF AAS; ${ }^{\mathrm{A}}$ - Limit calculated from the PDE daily dose ( $\mu \mathrm{g} /$ day) for a maximum daily drug dose of $10 \mathrm{~g} ;{ }^{B}$-Limits maximum described for PDEs of the elemental impurities of interest for a drug product taken by a patient; LOD -limit of detection - LOQ - the limit of quantification and RSD - relative standard deviation.

In Table 4, can be observed RSD values ranged from 1.5 to $10 \%$ for all analytes, in agreement with the USP<233> recommendations, that $\%$ RSD should be lower than 20\%. The LOD and LOQ are suitable for quantifying the eleven analystes of interest since the lower concentration limits by USP is $0.5 \mu \mathrm{g} \mathrm{g} \mathrm{g}^{-1}$ for $\mathrm{Cd}$ and $\mathrm{Pb}^{8}$. Through the PDE, we can observe that using the limit of quantification the methodology and maximum daily drug dose of $10 \mathrm{~g}$ (USP) the $P D E_{\text {calculated }}$ is much lower than the maximum limit of USP $<232>$, indicating that it is not at risk for patients. 
Table 5. Evaluation of accuracy (\%) at three different concentration levels.

\begin{tabular}{|c|c|c|}
\hline Element & $\begin{array}{c}\text { Detected } \\
\text { concentration }\left(\mu g \mathrm{~L}^{1}\right)\end{array}$ & $\begin{array}{c}\text { Accuracy } \\
\text { Spike recovery (\%) }\end{array}$ \\
\hline \multirow{3}{*}{ As } & 1.72 & 86 \\
\hline & 4.45 & 89 \\
\hline & 18.02 & 91 \\
\hline \multirow{3}{*}{ Cd } & 0.47 & 94 \\
\hline & 1.88 & 88 \\
\hline & 4.71 & 94 \\
\hline \multirow{3}{*}{$\mathbf{P b}$} & 5.55 & 111 \\
\hline & 22.51 & 97 \\
\hline & 50.10 & 104 \\
\hline \multirow{3}{*}{$\mathrm{Ba}$} & 30.28 & 101 \\
\hline & 63.83 & 91 \\
\hline & 132.64 & 88 \\
\hline \multirow{3}{*}{ Co } & 32.66 & 109 \\
\hline & 65.71 & 94 \\
\hline & 134.90 & 90 \\
\hline \multirow{3}{*}{$\mathrm{Cr}$} & 26.80 & 89 \\
\hline & 54.90 & 78 \\
\hline & 111.23 & 74 \\
\hline \multirow{3}{*}{$\mathrm{Cu}$} & 36.03 & 120 \\
\hline & 80.84 & 115 \\
\hline & 175.11 & 117 \\
\hline \multirow{3}{*}{$\mathrm{Fe}$} & 33.02 & 110 \\
\hline & 87.16 & 125 \\
\hline & 159.21 & 106 \\
\hline \multirow{3}{*}{ Li } & 032.36 & 108 \\
\hline & 77.35 & 110 \\
\hline & 163.39 & 109 \\
\hline \multirow{3}{*}{$\mathrm{Ni}$} & 30.61 & 102 \\
\hline & 62.90 & 90 \\
\hline & 130.86 & 87 \\
\hline \multirow{3}{*}{$\mathbf{v}$} & 30.99 & 103 \\
\hline & 69.16 & 99 \\
\hline & 147.92 & 99 \\
\hline
\end{tabular}

According to USP <233> requirements, acceptable spike recoveries should range between 70 and $150 \%$. For the first level, spiked recoveries between 86 - 120\% for all elemental impurities were obtained. For the second level, spiked recoveries ranged 
between 78 and $125 \%$. Finally, for the third level spiked recoveries between $74-117 \%$ were attained. The results obtained in this study were, therefore, satisfactory, demonstrating that the proposed multielemental method and the methodology for $\mathrm{As}, \mathrm{Cd}$ and $\mathrm{Pb}$ determinations are suitable for the purpose of this study.

The method uncertainty was calculated by taking into account the preparation of the analytical curve standards and samples, the analytical curve itself and, finally, sample repeatability. The standard operational procedure POP uncertainty sheet 65.3120.170 was used for the uncertainty calculation. $^{21}$

The relative uncertainty for the ICP OES analysis ranged from $42-52 \%$ for $\mathrm{Ba}, \mathrm{Co}, \mathrm{Cr}$, $\mathrm{Cu}, \mathrm{Fe}, \mathrm{Li}, \mathrm{Ni}$ and $\mathrm{V}$. The item that contributed the most to the relative uncertainty of each element were the standard solution preparations, with $80 \%$, sample preparations, with $17 \%$ and analytical curve preparations, with $3 \%$.

For GF AAS, the relative uncertainty for As $(16 \%)$ was more influenced by repeatability, contributing with $90 \%$, while for $\mathrm{Cd}(4.5 \%)$ and $\mathrm{Pb}(10 \%)$ analytical curve contributed with $72 \%$ and $77 \%$ of uncertainty, respectively.
3.2. Product analysis and active pharmaceutical ingredient (API) quantitation

A variation of mean weight was observed in relation to the different brands analyzed, variance 102.0-152.5 mg. but no tablet showed any result uniform in weight outside the range of $\pm 10 \%$.

In total, six $25 \mathrm{mg}$ captopril samples and one API sample showed satisfactory (less than the LOQ for most elements except iron for samples $A$ and $B$ ) results according to USP chapter $\langle 233\rangle$, corroborating previous studies performed in this area. In the study carried out by Muller, ${ }^{10}$ the only discordant result was for copper, at $3.41 \mu \mathrm{g} \mathrm{g}^{-1}$, above the value found herein. The results reported by Wollen (2015) are also in agreement with the results of the present study, where 6 final products and 4 API samples were analyzed.

The intra- and inter-batch evaluation for the elemental impurities evaluated herein in products from manufacturers $A$ and $B$ indicated that only iron concentrations differed between the different batches from brand $A$, with a variation between the results $\left(<1.5-3.0 \mathrm{mg} \mathrm{kg}^{-1}\right)$, albeit not statistically significant Table 6.

Table 6. Iron concentration in brand A and B captopril samples the different drug lots

\begin{tabular}{ccc}
\hline & \multicolumn{1}{l}{ Batch } & $\begin{array}{c}\text { Iron content in } \mu \mathbf{g ~ g}^{-1} \\
(\mathbf{n}=\mathbf{3})\end{array}$ \\
\hline \multirow{3}{*}{ A } & Lot 1 & 1.5 \\
& Lot 2 & 1.7 \\
& Lot 3 & 3.0 \\
& Lot 1 & 1.5 \\
& Lot 2 & 1.4 \\
& Lot 3 & 1.6 \\
\hline
\end{tabular}

Given the results of the determined elemental impurities and taking into account the maximum captopril dose that can be administered a day $(450 \mathrm{mg} /$ day $)$, corresponding to 18 tablets, it was possible to evaluate if the amount of ingested impurities was higher than the permissible daily exposures. The results varied from 
0.007 to $0.8 \mu \mathrm{g} /$ day, lower than the recommended PDE (Table 4). The quantified values are significantly below the permissible limit of $10 \mu \mathrm{g} / \mathrm{g}$ set by the EMA guideline and the USP <232> for oral exposure. These results are highlighted in Table $4 ., 22$

\section{Conclusions}

The chosen methodology was validated and applied for the quantitation of several elemental impurities in final pharmaceutical products and active pharmaceutical ingredients according to the new USP chapters <232> Elemental Impurities Limits and <233> Elemental Impurities. The methods presented optimal selectivity, linearity (0.9991), detection and quantification limits, relative standard deviations lower than $10 \%$ for precision, and recoveries higher than $90 \%$. All the studied samples presented satisfactory results regarding the presence of elemental impurities, below the limits established in the specific legislations. The evaluation of the inorganic composition of these products enables the knowledge of the inorganic profile of these products and ensures their quality. The calculation of the daily exposure was lower than the permissible daily exposure recommended by the USP, even if a patient were to ingest the highest allowable captopril dose described in the drug description leaflet, of $450 \mathrm{mg}$ (18 tablets - 25 $\mathrm{mg}$ )

\section{References}

${ }^{1}$ Støving, C.; Jensen, H.; Gammelgaard, B.; Stürup, S. Development and validation of an ICP-OES method for quantitation of elemental impurities in tablets according to coming US pharmacopeia chapters. Journal Pharmaceutical Biomedical Analysis 2013, 84, 209. [CrossRef] [PubMed]
${ }^{2}$ Rao, R. N.; Kumar Talluri, M. V. N. An overview of recent applications of inductively coupled plasma-mass spectrometry (ICP-MS) in determination of inorganic impurities in drugs and pharmaceuticals. Journal Pharmaceutical Biomedical Analysis 2007, 43, 1. [CrossRef] [PubMed]

${ }^{3}$ Agency for Toxic Substances and Disease Registry. ATSDR. ATSDR. Toxicological Profile for Lead. 2007 - Available from: https://www.atsdr.cdc.gov/toxprofiles/tp.asp ?id=96\&tid=22. Access: June 4, 2017

${ }^{4}$ The United States Environmental Protection Agency .EPA. Learn about Lead - Available from: https://www.epa.gov/lead/learnabout-lead\#effects. Access: June 4, 2017.

${ }^{5}$ Godt, J.; Scheidig, F.; Grosse-Siestrup, C.; Esche, V.; Brandenburg, P.; Reich, A.; Groneberg, D. A. The toxicity of cadmium and resulting hazards for human health. Journal Occupational Medicine Toxicology 2006, 1, 22. [CrossRef] [PubMed]

${ }^{6}$ Agency for Toxic Substances and Disease Registry. ATSDR. Toxicological Profile for Cadmium. 2012 - Available from: https://www.atsdr.cdc.gov/toxprofiles/tp.asp ?id=48\&tid=15. Access: June 4, 2017

7 The United States Environmental Protection Agency. EPA. Cadmium CASRN 7440-43-9. 1987. Available from: https://www.epa.gov/cadmium/learn-aboutcadmium\#effects. Access: June 4, 2017.

${ }^{8}$ The United States Pharmacopeia, Elemental Impurities - Limits 232: 2016a. Rockville: U.S. Pharmacopeia Convention, 2016.

${ }^{9}$ The United States Pharmacopeia, Elemental Impurities -Procedures 233 2016b. Rockville: U.S. Pharmacopeia Convention, 2016.

${ }^{10}$ Muller, A. L. H.; Oliveira, J. S. S.; Mello, P. A.; Muller, E. I.; Flores, E. M. M. Study and Determination of Elemental Impurities by ICP-MS in Active Pharmaceutical Ingredients Using Single Reaction Chamber Digestion in Compliance with USP Requirements. Talanta 2015, 136, 161. [CrossRef] [PubMed]

${ }^{11}$ Wollein, U.; Bauer, B.; Habernegg, R.; Schramek, N. Potential metal impurities in active pharmaceutical substances and finished medicinal products - A market surveillance study. European Journal 
Pharmaceutical Sciences 2015, 77, 100. [CrossRef] [PubMed]

${ }^{12}$ Gonzalez, M. H.; Silva, C. S.; Amaral, C. D. B.; Bianchi, S. R.; Oliveira, L. H. B.; Jéssica, S. Coelho, J. S.; Oliveira, A.; Nogueira, A. R. A. Determination of Elemental Impurities in Acyclovir Ointment and Raw Materials Using Microwave Acid Digestion (MW-AD) and ICPMS. Journal of the Brazilian Chemical Society 2017: 28 (1): 98-105.[CrossRef]

${ }^{13}$ Tavares, A. T. Master's dissertation. Instituto de Pesquisas Energéticas e Nucleares, ipen; 2013. [Link]

${ }^{14}$ Gang, L. I.; Schoneker, D.; Ulman, K. L.; Sturm, J. J.; Thackery, L. M.; Kauffman, J. F. Elemental Impurities in Pharmaceutical Excipients. Journal Pharmaceutical Sciences 2015, 104, 4197. [CrossRef]

${ }^{15}$ Ministério da Saúde. Medicamentos Disponibilizados Gratuitamente na Rede do Sistema Único de Saúde. SUS. Available from: http://www.pmpf.rs.gov.br/servicos/geral/fil es/portal/lista medicacao SUS.pdf Access: July 12, 2017.

${ }^{16}$ Programa Nacional de Verificação da Qualidade de Medicamentos- PROVEMEAvailable from: http://portal.anvisa.gov.br Access: July 12, 2017.
${ }^{17}$ Instituto Nacional de Metrologia Qualidade e Tecnologia. INMETRO. Coordenação Geral de Acreditação. DOQ-CGCRE-008: Orientação Sobre Validação de Métodos Analíticos. Rio de Janeiro, Brasil, 2016.

${ }^{18}$ Associação Brasileira de Normas Técnicas. ABNT NBR ISO/IEC 17025; Requisitos Gerais para a Competência de Laboratórios de Ensaio e Calibrações. Rio de Janeiro, Brasil, 2005.

${ }^{19}$ Souza, S. V. C.; Junqueira, R. G. A procedure to assess linearity by ordinary least squares method. Analytical Chimica Acta 2005, 552, 25. [CrossRef]

${ }^{20}$ Bazilio, F. S.; Bomfim, M. V. J.; Almeida, R. J.; Abrantes, S. M. P. Uso de planilha eletrônica na verificação da adequação de curva analítica ao modelo linear. Revista Analytica 2012, 59, 60.

${ }^{21}$ INCQS - Instituto Nacional de Controle de Qualidade em Saúde. Protocolo de validação e cálculo de incerteza para determinações de elementos inorgânicos por espectrometria POP no 65.3120.170. Rio de Janeiro, 2015.

${ }^{22}$ European Medicines Agency. EMA/CHMP/SWP/4446/2000 Guideline on the specification limits for residues of metal catalysts or metal reagents. London, 2008. 